\title{
Qualification and Certification of Thermographers
}

\author{
by $\mathrm{H}$. Heinrich \\ Universität Kaiserslautern, Bauphysik / Technische Gebäudeausrüstung / Baulicher Brandschutz \\ Erwin Schrödinger Straße, 67653 Kaiserslautern, E-mail: hheinric@rhrk.uni-kl.de
}

\begin{abstract}
:
A new three step qualification and certification system was developed using the European standard EN 473 as a basis. The courses are combined with an examination. The first courses at three different levels were succesfully carried out. In future actual standards are needed to perform a high quality education.
\end{abstract}

\section{Situation}

In the classic fields of Nondestructive Testing (NDT) as ultrasonic, X-ray and so on it is well known and common that the personnel is trained, qualified, examinated and certificated in a relatively uniform manner. But such a comprehensive practice was not known or usual in the past for Infrared Thermography (IT) in Europe. But in the United States those qualification standards are used for example by the American Society of Nondestructive Testing (ASNT).

In Germany in the past thermographers were only trained in some more or less basic short courses which were offered by the manufacterers of infrared camera system as FLIR or JENOPTIK and by their participation in conferences and seminars which were presented by the German thermographers association. To overcome this not very satisfactory situation the various observations were made. Finally the decision was made to use the European Standard EN 473 "Qualification and certification of NDT personnel" [1].

\section{European Standard EN 473}

The standard EN 473 is accepted today in eigtheen European countries. The standard explicit includes Infrared Thermography (IT). In the scope is clearly mentioned [1] that

$$
\text { "The system ... may also apply to Infrared Thermography (IT)". }
$$

Using the systematic of this standard in 1998 experts of the German thermographers together with external experts began to develop and later to establish a challenging and uniform educational program for thermographers.

\section{Certification}

After the courses an examination is offered and a successful examination will lead to an europewide accepted certification based on the European Standard. This certification will be confered by an independant certification body [1] unlike the United States, where a certification of a thermographer will by given by the employer and where exist no standard but only the SNT-TC 1A as a recommendation. These different systems are compared in figure 1.

\section{Training and Qualification}

The training and qualification concept is based on a three step course system. These three courses level I, level II and level III correspond to three different levels of knowledge and experience. 
A condition to participate the course level I is a minimum experience with IT of three months, for the course level II 9 months and for the course level III 12 to 72 months depending on the professional education of the thermographer.

The courses level I and II take five days (and an additional day for the examination) and the course level III takes four days (plus one examination day).

These durations correspond to a total of 40 hours of lectures for level I and also level II. For level III there is no fixed demand for the number of hours. These minimum experience and training requirements are shown in figure 2.

To give an impression of the contents of these courses a summery of the level II course is shown as an example in the following:

1. Basics

(Temperature, heat transfer)

2. Infrared radiation

3. Temperature Measurement

(Contact and Non-Contact)

4. IR Camera Systems and Performance Characteristics

5. IR Measurement

6. IR Reports and Software

7. Selected Applications:

Buildings

Industry

Electrical Application

Leakage Detection

8. Special Applications

In the year 1998 a first level III course was carried out with the aim to qualify a few (first) experts as teaching and examinating staff to run the following level II courses which were given at the Universities of Kaiserslautern and Rostock in 1999 [2]. In the year 2000 in consequence to this top -down model the first level I courses were held.

\section{Examination}

After the courses an examination is offered. A successful examination is the prerequisite for the later certification. The examination at all three levels consists of a general, a specific and a practical examination. In addition for level III a basic examination in NDT is requested.

For the general and the specific examination multiple choice questions have to be answered (see figure 3).

Because the later certification will be awarded in a "sector" due to EN 473 the thermographer has to choose in which sector (or sectors) he wants to be examinated.

There exist seven sectors:

1. Buildings $(B)$

2. Leakage Detection (L)

3. Electrical Applications (E)

4. Industry (I)

5. $N D T(N)$

6. Special Applications (S)

7. Multi-Sector ( $\geq 3$ Sectors)

The more theoretical general and specific examination is completed by a practical examination where the thermographers have to demonstrate their skills and their knowledge in a real or almost realistic situation.

The examination procedure is executed by a special examiner who is not a teacher in the course. 
The examiner is employed by an independent Certification Body. In our case the Certification Body is SECTOR CERT, Germany.

\section{Conclusion}

After the introduction of the new qualification and certification system the first thermographers could achieve their certificate which is europewide accepted. Participants in the first courses were not only Germans but also thermographers from Austria, Sweden and The Netherlands.

A problem is still the lack of practically usable and accepted standards. In the field of building thermography for example there exists only the ISO 6781 "Thermal performance of Buildings" [2] which was submitted in 1982(!) and which is no longer actual. In september 1999 a first step was made in Vancouver, Canada, to overcome this situation by establishing the subcommittee SC 8 "Infrared Thermography" in the ISO/TC 135 with the aim to create international accepted standards.

\section{References}

[1] EN 473 "Qualification and certification of NDT personnel”, 1992

[2] HEINRICH; H., "Thermography in Germany: state of the art", Thermosense XXII, Orlando, 2000, p.310-313

[3] ISO 6781 "Thermal performance of Buildings", 1982 


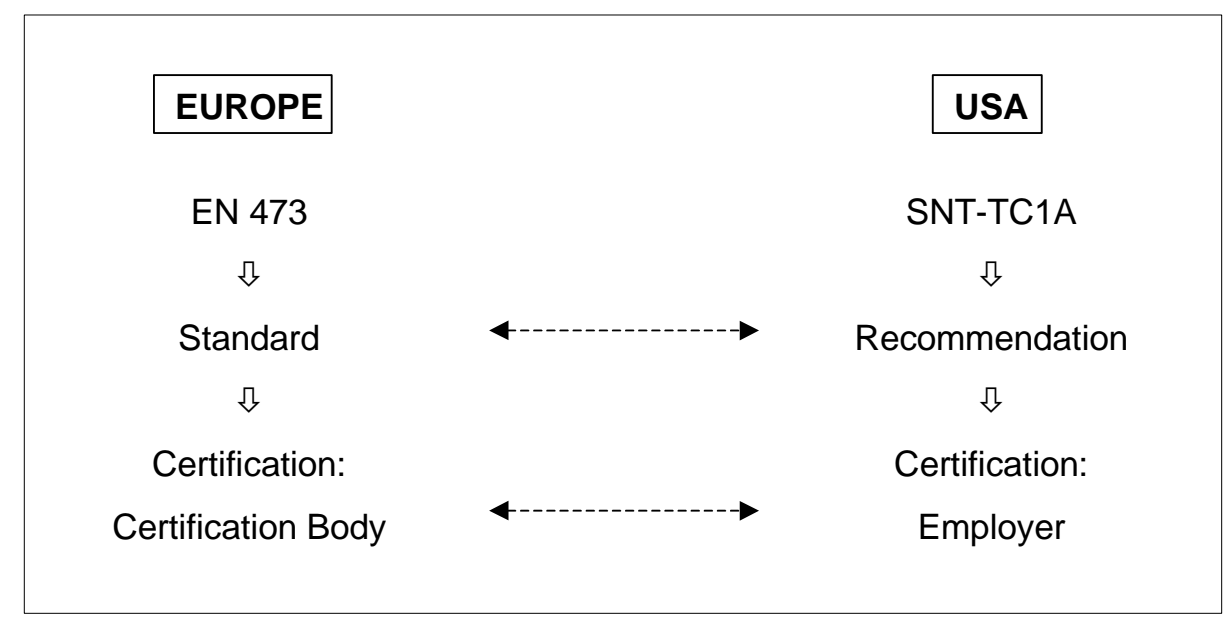

Figure 1 : Comparison of EN 473 with SNT-TC1A

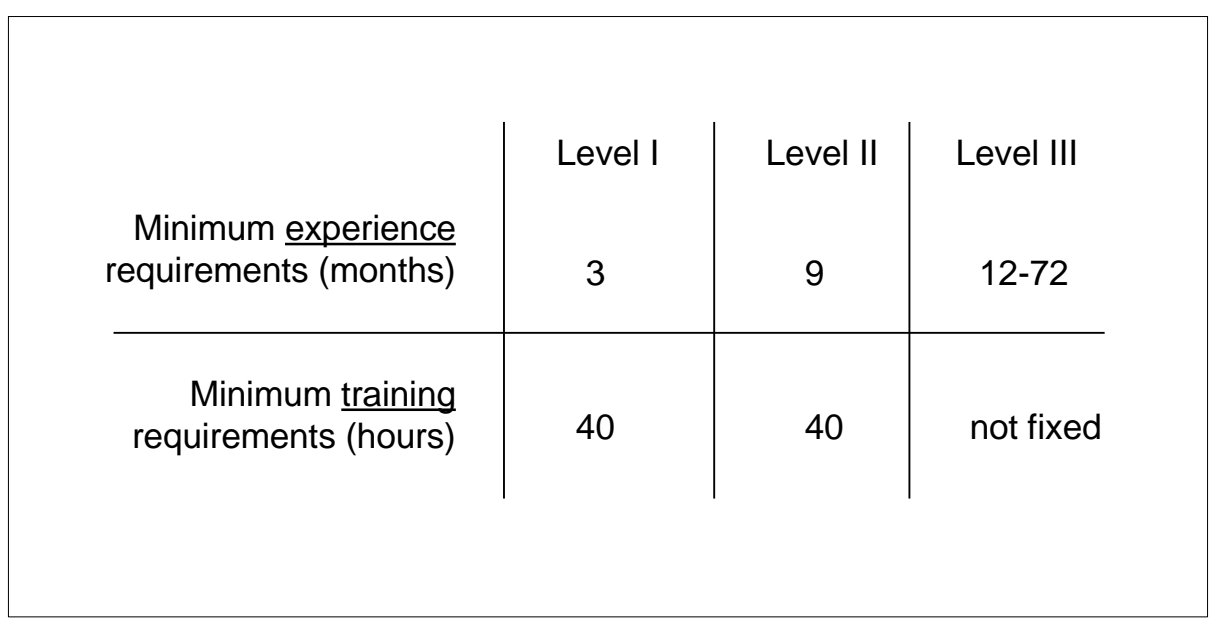

Figure 2: Minimum requirements for experience and training for the Infrared Thermography (IT) courses

\begin{tabular}{|l|c|c|c|}
\hline & Level I & Level II & Level III \\
\hline IT General examination & 40 & 40 & 30 \\
\hline IT Specific examination & $20(\ldots 30)$ & $20(\ldots 30)$ & $20(\ldots 30)$ \\
\hline NDT Basic examination & -- & -- & 85 \\
\hline
\end{tabular}

Figure 3 : Minimum number of questions for examination for the Infrared Thermography (IT) courses 